\title{
CERVEJA E NOTÍCIAS HÍBRIDAS: PUBLIEDITORIAIS NO G1
}

\author{
Beer and hybrid news: advertorials in G1
}

\section{Cerveza y noticias hibridas: publirreportajes en G1}

\section{Pablo Moreno Fernandes Viana}

Doutorando em ciências da comunicação pela Escola de Comunicações e Artes da Universidade de São Paulo, Brasil, e professor do Departamento de Comunicação Social da Pontifícia Universidade Católica de Minas Gerais, Brasil. Membro do Grupo de Estudos Semióticos em Comunicação, Cultura e Consumo (GESC3).

E-mail:pablomoreno@gmail.com

RESUMO Na contemporaneidade, a publicidade se sofistica, apresentando-se cada vez mais como conteúdo. Uma das formas para isso é hibridizar-se a outros tipos de conteúdo, como o jornalismo. Este artigo analisa publieditoriais, textos publicitários apresentados sob a forma de notícias, veiculados no portal G1 pelo anunciante Empório da Cerveja. Nessas notícias vê-se uma forma de comunicação que utiliza conteúdo jornalístico, com forte influência do jornalismo cultural, e constrói um imaginário de experiência de consumo, sem fazer menções diretas ao anunciante.

PALAVRAS-CHAVE Publieditorial, Consumo, Notícias, Publicidade contemporânea.

ABSTRACT In contemporary times, advertising is sophisticated, presenting becoming increasingly as content. One way to do this is hybridizing to other content, such as journalism. This article analyzes advertorials, advertising texts presented in the form of news, conveyed in G1 by the advertiser Empório da Cerveja. In these news you can see a form of communication that balances journalistic content, with strong influence of cultural journalism and builds imagination and consumption experience, without making direct references to the advertiser.

KEYWORDS Advertorial, Consumption, News, Contemporary advertising.

RESUMEN En la época contemporánea, la publicidad es sofisticado, presentando cada vez más como el contenido. Una forma de hacerlo es mediante hibridación con otros contenidos, tales como el periodismo. En este artículo se analiza publirreportajes, textos publicitarios presentados en forma de noticias, transmitidas en G1 por el anunciante Empório da Cerveja. En estas noticias ven una forma de comunicación que equilibra el contenido periodístico, con una fuerte influencia de periodismo cultural y construye la imaginación y el consumo de experiencia, sin hacer referencias directas al anunciante.

PALABRAS CLAVE Publirreportaje, Consumo, Noticia, Publicidad contemporánea. 


\section{INTRODUÇÃO}

Publicidade e jornalismo coexistem nos meios de comunicação, mas a fronteira entre eles sempre foi bem demarcada. O jornalismo era visto como o terreno da independência, da veracidade, da objetividade, da honestidade, da imparcialidade, da exatidão, da credibilidade (Bahia, 1990), enquanto à publicidade, com seu espaço delimitado por anúncios e linguagem apelativa, cabia o rótulo de pouco sincera, ilusória e sedutora (Luhmann, 2005).

Tem se tornado comum nos portais de notícias brasileiros o publieditorial, um formato particular de promoção do consumo, híbrido de publicidade e jornalismo (aproveita mais as características deste), que difere bastante dos anúncios disfarçados de notícia inseridos nos veículos com a identificação de “informe publicitário”, e chama atenção como objeto de estudo.

Este trabalho analisa essa modalidade comunicacional, verificando como os discursos da publicidade e do jornalismo são hibridizados para fins de promoção do consumo. A análise observa como o formato integra-se ao sistema publicitário, manifestando a expressividade marcária do anunciante.

\section{REFLEXÕES SOBRE JORNALISMO, CONSUMO E HIBRIDISMOS}

Notícia, na definição mais objetiva apresentada por Lustosa (1996, p. 17) “é o relato, não o fato". Cabe ao jornalista identificar a notícia em meio a um conjunto de acontecimentos. As informações são selecionadas para publicação por meio de critérios específicos - valores-notícia - e são transformadas utilizando-se técnicas específicas do jornalismo. $\mathrm{O}$ autor ainda conceitua que "notícia é o relato de um fenômeno social, presumivelmente de interesse coletivo ou de um grupo expressivo de pessoas" (Idem, p. 19).

Para construir uma imagem, as organizações recorrem a uma série de signos para compor sua expressividade marcária. $\mathrm{O}$ discurso publicitário, na intenção de atrair consumidores, apropria-se de outras formas de comunicação. Perez (2015, p. 2) explica que uma das características desse discurso reside na "exploração de diversas linguagens sobrepostas que convergem na busca da potencialização dos efeitos de sentido". Dentre essa ampla diversidade de formas de manifestação da marca, há de se destacar um formato que integra 0 discurso da propaganda aos conteúdos de mídia, em suas diversas manifestações, como o entretenimento e a produção noticiosa.

Conteúdo de marca, para Horrigan (2009, p. 59, tradução nossa), "permite pensar numa ausência de limites para estratégias de integração de marca”, e com isso amplia-se o potencial de exposição da marca, transportando-a para um contexto em que as audiências entram em contato com a mensagem a partir de outros processos de significação, com níveis de atenção maiores que os da propaganda tradicional.

O conteúdo de marca é produzido de forma híbrida (Covaleski, 2010), em sinergia com produtores de mídia. Trata-se de "um conceito estratégico que propõe outra maneira de entender a relação com o público, com base no conteúdo atraente e de qualidade, [co]produzido pela marca, para proporcionar uma experiência enriquecida" (Piñeiro Otero, 2015, p. 674, tradução nossa). Ele se manifesta mais 
especificamente em formas de produção que têm origem nas marcas, que passam a utilizar plataformas próprias para veicular conteúdos próprios. Corresponde a "uma forma de comunicação bem aceita, pois, de maneira mais sutil e menos invasiva que o bloco comercial, sugere ao consumidor que ele está sendo valorizado pelo anunciante" (Covaleski, 2013, p. 40).

A propaganda apresentada como peça jornalística já foi conhecida como "informação publicitária", "informe publicitário" ou "publieditorial". "É a propaganda feita com características editoriais, com formato bastante semelhante ao contexto do veículo onde é inserida e geralmente identificada de modo bem discreto" (Sampaio, 2003 p. 256). Essas integrações existem há tempos e, no Brasil, possuem regulamentação específica.

Zhou (2012, p. 324, tradução nossa), ao analisar a etimologia em inglês da expressão formada a partir da contração entre "publicidade" e "editorial" (advertorial), observa que a presença da publicidade no início da palavra a torna dominante na mensagem: "Como o próprio nome indica, um publieditorial tende a agir intrinsecamente como publicidade”.

O Código de Autorregulamentação Publicitária (Conar, 1980) define que "o anúncio deve ser claramente distinguido como tal, seja qual for a sua forma ou meio de veiculação". O Código especifica ainda que "a peça jornalística sob a forma de reportagem, artigo, nota, textolegenda ou qualquer outra que se veicule mediante pagamento deve ser apropriadamente identificada para que se distinga das matérias editoriais e não confunda o consumidor”.

A identificação publicitária, abordada em vários itens do Capítulo II do Código do Conar, regulamenta formas de garantir que o consumidor reconheça a mensagem publicitária como tal, determinando que o receptor não pode ser confundido sobre o anúncio no que diz respeito a sua forma de apresentação.

Um fato curioso refere-se ao item do código que condena explicitamente a publicidade que invade o espaço editorial ou tenta apropriar-se de seu repertório comunicacional para promover marcas, produtos e serviços: "Este Código condena os proveitos publicitários indevidos e ilegítimos, obtidos por meio de 'carona' e/ou 'emboscada', mediante invasão do espaço editorial ou comercial de veículo de comunicação" (Conar, 1980, art. 31).

Segundo dados do Instituto Verificador de Comunicação (IVC), em 2015 as principais empresas jornalísticas do Brasil perderam audiência, tanto no digital quanto no impresso (IVC BRASIL, 2015). Nesse contexto, Deak (2016) aponta que surgem "narrativas híbridas, que mesclam até mesmo outros campos menos associados ao jornalismo, como a arte, ou games, antropologia e exposições multimídia”. O hibridismo dessas narrativas começa a borrar as fronteiras entre jornalismo e outros campos, "não apenas no formato, mas no conteúdo e na sua produção e apresentação" (Idem). O autor destaca a convergência entre publicidade e jornalismo:

A publicidade também tem pontos de convergência com o jornalismo, quando busca alternativas no chamado branded content, conteúdo de qualidade patrocinado por marcas, e no storytelling, que nada mais é do que a narrativa bem contada que o jornalismo também persegue. (Idem) 
O publieditorial contemporâneo agrada tanto aos anunciantes, que se apropriam dos princípios jornalísticos, quanto às empresas de mídia, que ganham ao encontrar novas formas de manter os anunciantes. No entanto, precisa também agradar aos consumidores.

Companhias de mídia publicam publieditoriais e esforçamse para que pareçam reportar ou compartilhar informações úteis com os leitores. Em contraste, o objetivo final dos anunciantes é entregar mensagens comerciais e persuadir os leitores. Portanto, um compromisso precisa ser compartilhado entre a companhia de mídia e o anunciante. (Zhou, 2012, p. 328, tradução nossa)

Marshall (2003, p. 23) afirma que "o mercado tornou-se referência e paradigma, liberalizando os dogmas que sustentavam os mitos e ritos. Na verdade, o neoliberalismo transformou o mercado em uma espécie de 'totem social', para onde convergem os anseios e as expectativas da sociedade”. Esse totem social tem implicações significativas no fazer jornalístico, que é impactado em termos de circulação e faturamento, obrigando-o a se reinventar e abrir espaço - ainda que a contragosto para essa hibridação com a publicidade.

Assim, diante da perda de crédito da publicidade tradicional, a solução passa a ser pegar carona na credibilidade que ainda resta às notícias: "Não mais satisfeitas em ocupar os espaços próprios para a linguagem publicitária, as propagandas chegam a 'pular o muro' e invadir o território da informação, provocando uma forma mestiça de comunicação” (Idem, p. 41).

Enquanto tais combinações podem ser perigosas para o jornalismo, por sacrificarem a imparcialidade em nome de resultados comerciais, para a publicidade representam uma excelente oportunidade de contato com consumidores: "Informação e publicidade passam enfim a se fundir em um mesmo produto midiático. Cria-se uma notícia híbrida, uma metamorfose linguística, um amálgama de discursos” (Idem, p. 120). Essa forma híbrida torna-se realidade nos principais veículos de comunicação brasileiros, e atualmente há, inclusive, editorias exclusivas para a veiculação de conteúdos de marca editorial.

\section{VEÍCULO E O ANUNCIANTE: FRONTEIRAS BORRADAS}

O corpus analisado corresponde a publieditoriais veiculados no portal de notícias on-line do grupo Globo, o G1. Um dos principais representantes do ciberjornalismo brasileiro, o G1 é, segundo informações da Rede Globo, líder em audiência na categoria de notícias no país, contando com estrutura de atualizações 24 horas por dia. "Ciberjornalismo é a modalidade jornalística no ciberespaço fundamentada pela utilização de sistemas automatizados de produção de conteúdos que possibilitam a composição de narrativas hipertextuais, multimídias e interativas” (Schwingel, 2012, p. 37).

A diversidade de possibilidades em termos de organização e produção de conteúdo no ciberjonalismo propicia ganhos na elaboração da narrativa, mas também em termos de nível de informação. O ciberjornalista, a partir da apuração dos acontecimentos "pode transformar aqueles fatos em uma tela simples, ou desdobrá-la em diferentes níveis (um especial), com entrevistas inteiras, áudios, vídeos, animações, retrancas, galerias de fotos, infográficos interativos 
e mashups" (Idem, p. 111). Com essa possibilidade de sofisticação, as notícias tornam-se mais complexas, sendo acompanhadas, frequentemente, de recursos que ampliam a produção de conteúdo.

O anunciante em questão é o Empório da Cerveja, site de vendas diretas ao consumidor, de propriedade da Ambev, que opera em parceria com a B2W Digital, empresa de e-commerce brasileira. A marca comercializa cervejas nacionais e internacionais do portfolio da Ambev e também taças, copos etc.

As notícias são veiculadas numa editoria chamada "Somos todos Cervejeiros”. No jornalismo, a divisão em editorias serve para classificar os textos de acordo com seu conteúdo. "Cada editoria do jornal apresenta uma codificação diferente na formulação do texto da notícia. Os veículos de comunicação padronizam suas matérias na busca de uma narração que possa ser entendida ou decodificada por pessoas com diferentes repertórios" (Lustosa, 1996, p. 113).

Na seção “Anuncie Conosco" do portal G1 não há informações sobre esse formato de inserção. A única menção ao formato "informe publicitário" é apresentada no Manual de práticas comerciais da Globo.com:

A mensagem do anunciante não pode ser confundida com a informação/editorial/conteúdo das páginas do site. O material deve incluir a tarja "informe publicitário" nos casos em que há clara intenção do anunciante de fazer com que a mensagem publicitária seja entendida como notícia ou qualquer outro recurso disponível para identificar o anúncio. (Globo.com, 2012)

As chamadas para os textos aparecem acompanhadas de uma fotografia, da indicação da editoria a que pertencem, tempo de postagem e uma chamada. Lustosa (1996, p. 153) define as chamadas como "textos elaborados para a primeira página dos jornais, que objetivam despertar o interesse do leitor para as informações mais completas, que são editadas nas páginas internas”. A definição, embora refira-se ao impresso, serve também para o ciberjornalismo. Entre as chamadas da página inicial há algumas que aparecem sinalizadas como "Especial Publicitário", no lugar da editoria. Fora isso, a estrutura é a mesma das demais chamadas de caráter puramente noticioso.

Em uma notícia, é função do título "atrair a atenção e dar uma ideia geral dos fatos. Mas sobretudo, anunciar o fato, resumir a notícia” (Idem, p. 149). Essa função desperta a curiosidade dos leitores, apresentando um curtíssimo resumo da notícia, e possui também uma estrutura padrão de composição: "Tendo necessariamente de anunciar o acontecimento e resumir a notícia [...], o título deve de preferência carregar um verbo de ação, evitar o uso de artigos, não repetir palavras e ser essencialmente afirmativo" (Bahia, 1990, p. 48).

No que se refere à construção do texto jornalístico, a forma padrão é chamada de pirâmide invertida. Essa estrutura traz, após o lead, as informações em ordem decrescente de importância na mensagem. Nessa forma de composição, segundo Erbolato (1991, p. 66), o texto é organizado a partir da seguinte sequência: “a) entrada ou fatos culminantes; b) fatos importantes ligados à entrada; c) pormenores interessantes; d) detalhes dispensáveis”.

O lead encontra-se geralmente no primeiro parágrafo da notícia. Tem como função “informar imediatamente o leitor das características 
mais importantes do fato que se noticia; e serem atraentes apelando à leitura do resto do texto" (Gradim, 2000, p. 57). O lead, como explica a autora, deve responder seis questões fundamentais: O quê?, Quem?, Quando?, Onde?, Por quê? e Como?. Essa estrutura de formulação corresponde "às perguntas que a generalidade das pessoas coloca quando deseja inteirar-se de um acontecimento" (Idem, p. 58).

Todos os textos selecionados apresentam a estrutura por blocos, que podem conter subtítulos dividindo os assuntos para sinalizar mudanças de tema ou aprofundamento em algum tópico específico.

Durante o processo de coleta, foi possível notar forte influência do jornalismo cultural. Esse gênero do discurso jornalístico diferencia-se das chamadas hard news (notícias sobre acontecimentos mais marcantes em termos de fato, como os que são apresentados nas editorias Cidades, Policial, Economia etc.), pois dá mais destaque, como explica Piza (2010, p. 80), "à agenda de lançamentos e eventos (livros, shows, exposições etc.): olham mais para o que vai acontecer do que para o que está acontecendo ou já aconteceu”.

Assim como nas demais editorias, no jornalismo cultural há espaço para notícias. "Nesses casos, como em qualquer modalidade de jornalismo noticioso, o repórter cultural apenas tem a ganhar se possui, além de domínio no assunto e criatividade na abordagem, persistência na apuração e imparcialidade no relato” (Idem, p. 80). O autor ainda explica que o jornalista cultural deve ser criativo ao levar as novidades a seu leitor, por meio de uma pesquisa aprofundada e um relato isento dos fatos.

O jornalismo cultural abrange ainda matérias do tipo de apresentação, que, segundo Piza (2010, p. 81), têm como função familiarizar o leitor a algo que lhe é desconhecido. Ele destaca, no entanto, que "nesses casos, porém, uma dose maior de subjetividade - olhar interpretativo, passagens em tom de comentário - é até bem-vinda”.

O autor aborda também as efemérides, datas importantes para se produzir notícias - no jornalismo cultural - sobre assuntos que são relembrados. Piza (2010, p. 81) explica que "a data pode ser ótimo pretexto para lançar luz sobre aspectos menos conhecidos ou reavaliar essas consagrações”. Utilizam-se as perspectivas histórica e crítica para dar luz a esses eventos na rotina do jornalismo cultural.

\section{Samba e cerveja}

A primeira notícia ${ }^{1}$ foi veiculada em 11 de fevereiro de 2016 e aparecia em destaque na página inicial do G1 na ocasião da coleta. Trata-se de uma efeméride, por abordar a comemoração dos 100 anos de samba. Nota-se, desde o tema da notícia, estreita relação com 0 gênero cultural.

A manchete, composta por uma fotografia e o texto da chamada, tem a função de despertar a curiosidade dos leitores, estimulando o clique no link: "Nas chamadas são feitas indicações sobre a matéria, visando a despertar o interesse sobre o assunto narrado" (Lustosa, 1996, p. 151).

Ao clicar, antes de carregar o texto completo, uma janela vermelha é exibida, pedindo que o navegante confirme possuir mais de 18 anos. Essa tela atende a uma exigência do item "d" do princípio da proteção

1. A dama de honra do samba. Disponível em: http://glo.bo/2eumw0x 
a crianças e adolescentes do Conar, que afirma que "os websites pertencentes a marcas de produtos que se enquadrarem na categoria aqui tratada deverão conter dispositivo de acesso seletivo, de modo a evitar a navegação por menores” (Conar, 2008, Anexo A). Ao clicar em Sim, o texto se abre. Como tal obrigatoriedade é exclusiva do universo da propaganda, ao ver essa mensagem, torna-se mais evidente para o receptor a função publicitária do texto.

Uma tarja laranja traz a identificação "Especial Publicitário", obedecendo novamente aos princípios regulamentares do Conar e demonstrando preocupação com a questão da ostensividade da identificação publicitária. O título do texto foge ao padrão jornalístico, por não trazer um verbo. No entanto, essa fuga não sinaliza para a publicidade, e sim para uma escrita mais literária, outra característica do jornalismo cultural. Em seguida, há um subtítulo, cuja função é complementar a informação do título, introduzindo mais informações sobre o texto, com mais características de jornalismo.

No lead, embora sua estrutura não seja tão direta e esquemática, nova referência a textos do jornalismo cultural, é possível encontrar respostas ao O quê?, Quem?, Quando?, Como? e Por quê?.

São apresentadas informações que contextualizam a relação entre samba e cerveja, com a fala de um músico de uma das mais importantes rodas de samba do Rio de Janeiro, que endossa, como fonte direta, o título da notícia, promovendo a relação entre cerveja e samba. "Em todas as notícias as fontes desempenham um papel fundamental" (Bahia, 1990). As fontes contribuem para a qualidade da informação produzida, enriquecendo a história que é contada, além de trazer mais veracidade ao relato por meio das aspas, que funcionam como comprovação do que é afirmado. Outra fala de fonte direta, de um historiador, visa trazer legitimidade ao texto com o olhar de alguém que estuda o tempo e os acontecimentos para justificar a relação proposta no título.

A primeira parte da notícia é acompanhada de uma fotografia, ao lado do lead, e traz vários elementos que fazem referência à expressividade marcária da cerveja Antarctica (copos azuis e pinguins - a mascote da marca), inclusive na legenda.

Os entretítulos sinalizam para mudanças de abordagem na estrutura do texto, introduzindo um novo bloco, mas sem fugir da temática original. Segundo Lage (1999, p. 52), "o emprego de entretítulos varia de acordo com a natureza do texto”. Nessa notícia, nota-se a partir daí um distanciamento mais notório com o texto jornalístico, aproximando-se mais do híbrido com a publicidade, por conta de menções mais claras à cerveja Antarctica:

Os princípios do jornalismo vetam a promoção ou evocação, intencional ou não, de qualquer tipo de marca, empresa, produto ou serviço no espaço editorial. A cartilha reza que tal situação jornalística, quando for necessária, deve preservar o anonimato e impedir que a seção redacional seja explorada por objetivos escusos.

(Marshall, 2003, p. 133)

Passa a ser abordado o camarote da BOA - espaço patrocinado pela cerveja Antarctica no carnaval do Rio de Janeiro. O texto promove a relação entre o camarote, o sambódromo do Rio de Janeiro e à homenagem aos 100 anos do samba. Entra aí a fala da diretora de marketing da Antarctica, patrocinadora do camarote, que aborda, como 
fonte direta, a tradição do samba. Neste momento, pela primeira vez em todo o texto, há menção nominal à cerveja. A marca é personificada como uma entidade, um sujeito. Uma fotografia integra a notícia nesse subtítulo e traz referências à Antarctica, apresentando seu logotipo (em destaque ainda maior que a primeira), assim como suas cores institucionais. A referência também aparece na legenda, por meio da menção ao Camarote BOA.

O texto passa a explicitar mais a marca, trazendo vários elementos de sua expressividade marcária (nome da marca, nome do camarote que faz referência ao tema da campanha publicitária, representações das cores da marca na fotografia).

Segue-se um novo entretítulo, com uma linha do tempo que traz fatos curiosos sobre o samba de 1916 a 2016, incluindo seis menções à cerveja Antarctica, em datas diversas. Após a linha do tempo, há uma foto de vários sambistas em frente a um painel do Camarote BOA, em que a marca está coberta pelas pessoas e a legenda não traz citações diretas à cerveja. No entanto, a fotografia possui, no canto superior direito a sinalização "Beba com moderação", em atendimento ao artigo 44 do Anexo A do Código do Conar (2008).

\section{Anti-bar e o conceito de cerveja}

A segunda notícia ${ }^{2}$ foi publicada em 20 de janeiro de 2016, tendo sido editada um dia depois. A possibilidade de edição do texto, inserindo atualizações e registrando o histórico de modificações, é característica do ciberjornalismo. O texto aborda uma informação curiosa para o leitor, trazendo dados sobre o anti-bar. Percebe-se a intenção de familiarizar o público com algo desconhecido, trazendo significativas doses de subjetividade e o olhar interpretativo do autor - novamente, uma relação estreita com o jornalismo cultural.

O título, diferentemente da primeira reportagem, é mais longo e ocupa duas linhas, aproximando-se mais da forma tradicional do jornalismo em termos de estrutura: tem um verbo e instiga mais a curiosidade do leitor. $\mathrm{O}$ título mais longo é característico do ciberjornalismo, mais fluido em termos de diagramação que o jornalismo impresso. Assim como no primeiro caso, há um subtítulo que complementa as informações apresentadas.

Outra variação em relação ao jornalismo tradicional é a aparição do lead. Apresentado somente no segundo parágrafo, o primeiro bloco de texto faz uma introdução ao assunto sem informações objetivas, fugindo do padrão de composição textual da pirâmide invertida. Esse parágrafo introdutório pode ser classificado como nariz de cera. Criticado pelos principais manuais de jornalismo, "o nariz de cera aparece associado a uma narrativa disfuncional, subjetiva e inadequada à velocidade da vida nos tempos modernos" (Silva, 2009, p. 6).

Apesar da crítica ao nariz de cera, Piza (2010) lista uma pequena abertura do texto como uma dica para o jornalista cultural: "Faça uma abertura de texto atraente, sem demorar demais a introduzir o leitor no ponto central da história” (Piza, 2010, p. 86). Nota-se, portanto, maior liberdade criativa na construção de textos para o jornalismo cultural que para os demais gêneros. Em outro conselho, o autor pede mais liberdade criativa a quem escrever textos com características culturais:

2. Disponível em: http://glo.bo/2esUas0 
"Manuais de redação são apenas para orientação e padronização. Nenhuma 'objetividade jornalística' implica não usar metáforas, riqueza verbal, humor” (Idem, p. 87).

$\mathrm{O}$ lead responde às questões fundamentais da estrutura jornalística. Entretanto uma coisa incomum em textos que utilizam a pirâmide invertida é usar perguntas, presentes no texto e respondidas já na frase seguinte - isso também remonta a um texto mais literário. 0 proprietário do bar abordado na notícia aparece como fonte direta, sendo apresentado como uma referência no ramo de cervejas. Para justificar a informação, explica que tem ampla trajetória no segmento, citando algumas cervejarias para as quais trabalhou. Nesse momento há menção às marcas de cerveja Brahma e Antarctica, rompendo também com o anonimato de marcas no texto jornalístico, mas de forma menos marcante que na notícia anterior.

Um aspecto diferente da primeira reportagem, em termos de conteúdo, é que há apenas uma foto, em tamanho mais amplo, que traz a fachada do bar. Outro diferencial é uma área com um link "Saiba Mais”, que traz um álbum de fotos. Esse recurso explora o potencial hipertextual da mensagem do ciberjornalismo, permitindo sua ampliação por meio de outros recursos multimídia.

\section{E ONDE ENTRA O ANUNCIANTE?}

Nas notícias há menções a marcas de cerveja. Ao mesmo tempo, seja na chamada na página principal do G1, seja ao longo do texto, aparece o nome Empório da Cerveja, por meio de seu logotipo (no caso da chamada) ou na declaração de responsabilidade no início dos textos. Em todas as notícias do G1 há espaço para a inserção de publicidade ao longo dos textos. Geralmente, são inseridos no canto superior direito, ao lado dos conteúdos relacionados à notícia, e variam toda vez que a página é atualizada. O único anunciante exibido é o Empório da Cerveja, independentemente de quantas vezes a página seja recarregada.

Na interface do G1, ao fim de um texto, há espaço para comentários e compartilhamentos. No entanto, nesses publieditoriais estudados não há opção de comentar, restringindo novamente uma das características do ciberjornalismo, que é a possibilidade de interação. No lugar da caixa de comentários há nova publicidade, maior que a superior, assinada por Somos Todos Cervejeiros. Após o anúncio, há opções de compartilhamento em redes sociais, via e-mail etc.

As notícias não mencionam de forma direta o anunciante, o Empório da Cerveja. No entanto, são citadas as marcas comercializadas no site - todas de propriedade da Ambev. A menção a produtos aparece contextualizada no conteúdo jornalístico: na primeira, a gerente de marketing da Antarctica; na segunda, o proprietário do anti-bar. Todos aparecem como fontes diretas. Embora isso sinalize desrespeito aos princípios do jornalismo, demonstra preocupação do anunciante em oferecer conteúdo. Como são produtos que pertencem ao portfólio de um mesmo grupo, pode-se afirmar que, indiretamente, os benefícios da menção e a sutileza do ocultamento de quem financia a mensagem recaem como resultado positivo para a Ambev.

Há de se reconhecer o esforço em construir narrativas que se distanciam de um apelo promocional. A não ser nos anúncios presentes, o publieditorial mantém relativa sobriedade, típica ao jornalismo. Ainda 
assim, aproveitando-se da chancela "isenta", colocada pelo conteúdo jornalístico do G1 e pela forma do texto, há exposição das marcas.

Por se tratar de produto que possui regulamentação específica do Conar, destaca-se a eficiência do anunciante em atender às exigências colocadas pelo artigo 44, Anexo A.

deverá ser estruturada de maneira socialmente responsável, sem se afastar da finalidade precípua de difundir marca e características, vedados, por texto ou imagem, direta ou indiretamente, inclusive slogan, o apelo imperativo de consumo e a oferta exagerada de unidades do produto em qualquer peça de comunicação. (Conar, 2008)

Chama atenção, inclusive, o atendimento à cláusula de advertência inserida na maior parte das fotografias, demonstrando preocupação com o instrumento de autorregulamentação, embora não haja cláusulas específicas para a inserção de imagens nos informes publicitários.

Paparounis (2014), ao debater sobre a eficiência do publieditorial, aborda situações em que o formato coloca-se como estratégia válida. A primeira delas é para explicar ideias complexas. Nos casos analisados, pode-se reconhecer a eficiência, uma vez que, embora o e-commerce seja um setor com crescimento permanente nos últimos anos, ainda não é muito comum a ideia de se comprar cerveja via Internet. A segunda é para ensinar a usar o produto. Não é o caso das notícias analisadas, uma vez que nenhuma delas aborda especificamente o Empório da Cerveja, muito menos sua logística de vendas. O terceiro propósito é quando se quer reforçar valores de marca. Embora a marca anunciante não seja citada, os produtos comercializados por ela são inseridos na narrativa jornalística, despertando de alguma forma a curiosidade ou a vontade pelo consumo do produto.

Outro momento diz respeito a gerar confiança. Quando se iniciou o levantamento dos materiais a serem analisados, e o Empório da Cerveja emergiu como objeto empírico, foi realizada busca no Google por mais informações sobre a marca. Uma das sugestões de pesquisas relacionadas era "Empório da Cerveja é seguro", entre outros. Dessa forma, nota-se, segundo o algoritmo do Google, que há buscas sobre a confiabilidade da marca por potenciais consumidores. Assim, associar o nome da marca a conteúdo do G1 é uma estratégia eficaz para agregar o valor de confiança.

O último propósito apontado pelo autor diz respeito a humanizar a empresa. Nessa estratégia, mostra-se quem são as pessoas por trás do negócio. No caso do Empório da Cerveja, oferecer conteúdo editorial sobre o universo da cerveja sem estimular o consumo direto cria uma relação de proximidade com o consumidor, atentando-se para a lógica da contemporaneidade e reconhecendo sua importância histórica em relação a um dos mais tradicionais ritmos do país, ou como se pode ter experiências curiosas por meio da visita ao anti-bar.

\section{CONSIDERAÇÕES FINAIS}

Notícias relatam acontecimentos reais, o que sinaliza para um respeito aos princípios do jornalismo, no tocante a veracidade e honestidade. Entretanto, o princípio da imparcialidade não é respeitado, pois são 
mencionadas somente marcas da Ambev. O mesmo pode ser afirmado sobre o princípio da objetividade: somente no texto que discute os 100 anos do samba há relevância noticiosa.

Há de se reconhecer que a sinalização do conteúdo como "Especial Publicitário" e a indicação de quem é o anunciante tentam neutralizar o desrespeito ao princípio da imparcialidade, deixando claro - pelo menos no atendimento a regras do Conar - que se trata de propaganda e quem banca aquela mensagem.

A menção aos produtos comercializados destaca a estratégia do publieditorial. A organização quer agradar os consumidores, aproximando-se deles sem fazer um convite direto ao consumo. Para isso, ao invés de se colocar na estrutura da notícia, apresenta os produtos que comercializa, dando a eles verniz noticioso, transformando-os em pauta, fonte ou cenário.

As marcas, no entanto, devem levar em consideração o papel do sujeito contemporâneo e sua necessidade permanente de satisfação, o que inclui a consciência sobre seus direitos enquanto consumidor. o papel do jornalismo, nesse contexto, deve ser objetivamente problematizado por pesquisadores da área, que precisam debater essas relações, avaliando seus riscos e impactos para os valores fundamentais da atividade.

\section{REFERÊNCIAS}

BAHIA, J. Jornal, história e técnica. 4. ed. São Paulo: Ática, 1990.

CONAR. Código Brasileiro de Autorregulamentação Publicitária. São Paulo, 1980.

Disponível em: http://bit.ly/2esFMjr. Acesso em 20 out. 2016.

Resolução nº 01/2008. Complementa o Anexo "A" - Bebidas Alcoólicas, do

Código Brasileiro de Autorregulamentação Publicitária. São Paulo, 18 fev. 2008.

COVALESKI, R. Publicidade hibrida. Curitiba: Maxi, 2010.

Idiossincrasias publicitárias. Curitiba: Maxi, 2013.

DEAK, A. Conheça 60 casos de narrativas inovadoras do jornalismo. Huffpost Brasil, São Paulo, 11 jan. 2016, Seção Blog. Disponível em: http://bit.ly/2erxEOJ. Acesso em 13 jan. 2016.

ERBOLATO, Mário L. Técnicas de codificação em jornalismo: redação, captação e edição no jornal diário. 5. ed. rev. e aum. São Paulo: Ática, 1991.

GLOBO.COM. Manual de práticas comerciais. 2012. Disponível em: http://glo.bo/2dJGeXC. Acesso em 26 jan. 2016.

GRADIM, A. Manual de jornalismo. Covilhã: Universidade da Beira do Interior, 2000.

HORRIGAN, D. Branded content: a new model for driving tourism via film and branding strategies. Tourismos - An International Multidisciplinary Refereed Journal of Tourism, v. 4, n. 3, p. 51-65, 15 nov. 2009

IVC BRASIL. Saiba como usar o adblock detector. IVC New!, São Paulo, 2 fev. 2016. Disponível em: http://bit.ly/2eitVVi. Acesso em 7 fev. 2016.

LAGE, N. Linguagem jornalística. 6. ed. São Paulo: Ática, 1999.

LUHMANN, N. A realidade dos meios de comunicação. São Paulo: Paulus, 2005.

LUSTOSA, E. O texto da notícia. Brasília: Ed. UnB, 1996.

MARSHALL, L. O jornalismo na era da publicidade. São Paulo: Summus, 2003.

PAPAROUNIS, D. O publieditorial que funciona. meio \& mensagem, 11 ago. 2014, seção

Ponto de Vista. Disponível em: http://bit.Iy/VA1ZMY. Acesso em 16 abr. 2016.

PEREZ, C. Estéticas do consumo a partir do sistema publicitário. In: XXIV ENCONTRO 
NACIONAL COMPÓS, Brasília, 2015. Anais. Disponível em: http://bit.ly/2eioUwe. Acesso em 06 jan. 2016

PIÑEIRO-OTERO, T. Del jingle a las radios corporativas: una aproximación al concepto de audiobranding. Prisma Social, Madri, n. 14, p. 663-668, nov. 2015.

PIZA, D. Jornalismo cultural. 2. ed. São Paulo: Contexto, 2010.

SAMPAIO, R. Propaganda de A a Z: como usar a propaganda para construir marcas e empresas de sucesso. 3. ed. Rio de Janeiro: Elsevier, 2003.

SCHWINGEL, C. Ciberjornalismo. São Paulo: Paulinas, 2012.

ZHOU, S. Advertorials: A genre-based analysis of an emerging hybridized genre. Discourse and Communication, v. 6, n. 3, p. 323-346, 2012. 